Journal of Business and Economics Review

Journal homepage: www.gatrenterprise.com/GATRJournals/index.html

J. Bus. Econ. Review 1 (1) $78-83$ (2016)

\title{
The Impact of Minimum Wage Policy on Small Medium Enterprises' Productivity in the Manufacturing Sector
}

\author{
Ung Leng Yean ${ }^{1 *}$, Tee Peck Ling ${ }^{2}$, Chung Chay Yoke ${ }^{3}$, Jayamalathi Jayabalan ${ }^{4}$, \\ Pok Wei Fong ${ }^{5}$ and Shamini Kandasamy ${ }^{6}$ \\ 1,2,3,4,5,6 Universiti Tunku Abdul Rahman, Kajang, 43000, Selangor, Malaysia
}

\begin{abstract}
Objective - This study's aim is to identifies the minimum wage policy implementation and its impact on SMEs in Malaysia. It addresses the question of the level of SME's awareness and their readiness towards the implementation of the policy and improving productivity.

Methodology/Technique - Data were collected through questionnaire distribution and literature study. Analysis was conducted via a descriptive method.

Findings - The solutions identified in addressing the problem include the need to increase labour productivity, lower operational costs and change organizational methods.

Novelty - The discussions of this paper provide an in-depth understanding of the issues related to how the policy affects company's competitive advantage and financial performance.
\end{abstract}

Type of Paper: Empirical

Keywords: Minimum Wage Policy; Malaysia; SMEs, Manufacturing Sectors; Productivity.

JEL Classification: E24, L60.

\section{Introduction}

The minimum wages initiative is as one of the policy instruments recommended by the New Economic Model (NEM). Its purpose is to ensure inclusiveness by transforming the economy from a middle-income nation to a high-income one by the year 2020. The Minimum Wages Order 2012 was announced to be effective from January 1, 2013 for employers with more than six employees. As for firms with less than five employees, the policy was to be effective from July 1, 2013. The minimum wages initiative, however, was only fully gazetted and applied to all firms on January 1, 2014. This initiative set the minimum wage of RM900/month (RM4.33 per hour) for Peninsular Malaysia and RM800/month (RM3.85 per hour) for Sabah, Sarawak and Labuan. It covers both the local and foreign workforce, excluding domestic helpers and gardeners. The concept

\footnotetext{
* Paper Info: Received: September 21, 2016

Accepted: December 24, 2016

* Corresponding author:

E-mail: ungly@utar.edu.my

Affiliation: Faculty of Accountancy and Management, UTAR, Malaysia
} 
of minimum wages refers to the basic wage. It excludes any allowances or other payments. It is also applicable to employees who are paid on piece-rates, tonnage, trips or commission-based arrangements. Employers are required to supplement the wages of these employees if their income does not meet the minimum wages policy standard.

Through the recommendation, it is expected that the cost of doing business will increase drastically, especially for those in the low paying sectors. Firms that employ large numbers of foreign workers specifically, the small and medium enterprises (SMEs), are thus expected to be using various strategies as a means of improving productivity and to adapt to the costs increased due to the new wage policy.

This study focuses on looking at the impact of the Minimum Wage Policy on SMEs specifically, on the manufacturing sectors. Based on their firm size, SMEs account for $97.3 \%$ of the total business establishments of the nation, contributing $33.1 \%$ of the GDP, $57.5 \%$ of employment rate and $19 \%$ of exports. Out of this total, $77 \%$ of SMEs fall under the category of micro sized businesses (less than 5 workers); $20 \%$ of firms are small sized businesses (less than 30 workers) and only $3 \%$ are medium sized businesses (less than 75 workers) (see Cairo AMC-CBE-WBG, 2015). The Malaysian government is committed to ensuring that SMEs contribute $40 \%$ to the GDP by the year 2020. Based on the issues of improving productivity and adapting to the cost increase, this study aims to identify the implementation of minimum wage policy and its impact on SMEs in Malaysia. The study will also address the question of the level of SME's awareness and their readiness towards the implementation of the policy and improving productivity. The study provides an in-depth understanding of the issues related to how the policy affects company's competitive advantage and financial performance. This research thus aims to answer the question of "Is the minimum wage policy a strategic approach in strengthening SMEs' productivity and performance?"

\section{Literature Review}

There are various studies looking at productivity as a research area and many of them measure productivity based on single factors or multifactor. With the minimum wage policy being introduced throughout the country, employers are concerned about the impact of this policy on their firm's productivity. This is because their level of awareness and readiness is perceived to be a steep learning curve for most. According to a research done by an international labour organization (Global wage report, 2012/13), most countries such as Denmark, France, Finland and the UK do experience close relationships between wage and productivity growth. However, countries like the US, Japan and Germany seem to be experiencing productivity growth in spite of the average decline in wage rate. These results can be explained by the high competitiveness noted in the labour market, the good work ethics in the organization culture and other benefits offered by the firms. In the ASEAN region, especially Thailand, even though the policy has brought positive impact to productivity growth which has grown by $12 \%$, unemployment rate has increased by $0.8 \%$ (Sin Chew Jit Poh, 2013). Therefore, the impact has to be evaluated from various aspect.

A number of studies had considered looking at specific channels which could show that an increase in minimum wage would increase firms' productivity. In their study, Riley and Bondibene (2015) found evidence to suggest that increase in firms' labour costs due to minimum wage policy were accompanied by increase in firms' labour productivity, which leads to total factor productivity.

The research done by Fuss and Wintr (2012) evaluated the elasticity of firms' employment and real average labour compensation to total factor productivity. It was found that productivity improvement was due to workers' effort due to the higher wage rate. (Shapiro \& Stiglitz, 1984). In contrast, Frick et al. (2013) noted that performance based on pay will have a negative impact on productivity and this partially supports the findings of Gomez et al. (2007)

Dogan et al. (2013) also conducted a research on productivity based on manufacturing firms with different operation scales. They found that large firms tend to be more productive than medium or small firms. 
All of these studies provide some evidence which show that there is a link between an increase in minimum wage rate and productivity. This outcome is also supported by the report noted by the Low Pay Commission Report of 2011 which asserted that the positive impact can be seen in low pay sectors especially, in large firms. The reason for this, it is claimed, is because larger firms could pass on their increase costs to customers as well as be able to reorganize their productive schedules.

The Small and Medium Institute of Employers (SMI) highlighted that 80\% of the SMEs could be shut down if this policy is implemented (The Star, 2012). This was concurred by the Edge (2012) which stated that this is expected as firms' level of readiness is low since they rely heavily on labour.

\section{Research Method}

This study relies on primary data which were collected through two methods: a survey based on a structured questionnaire and semi structured panel discussions. Descriptive statistics such as frequency count was used to analyse the primary data and secondary data pertaining to SMEs' awareness and readiness towards minimum wage implementation.

Questionnaires were distributed to a sample of 50 SME manufacturing companies in the Klang Valley and they were stratified according to firm size. (See Table 1). The targeted respondents comprise firm owners or managers who have knowledge of the financial information and the operation details of the respective company. The response rate is $78 \%$. Analyses were performed based on a total of 188 responses, where some sample firms being surveyed had more than one owner and manager who responded. Data collected were coded and analysed with the aid of the SPSS software.

Table 1. Responses to the survey based on size (\%)

\begin{tabular}{|c|c|c|}
\hline Micro & Small & Medium \\
\hline 20.5 & 38.5 & 41 \\
\hline
\end{tabular}

\section{Research Result}

The findings emphasized the comparison of SMEs in the manufacturing sector which are of different sizes because the size of a company determines the resources and capacity to be allocated to devise and implement the company's strategic plan on productivity.

The awareness and readiness of the SMEs involved are discussed based on four major areas of practices as shown in Table 2. The four major areas of practices are listed below:

- Manage productivity projects and processes

- Conduct a productivity prognosis

-Increase productivity one area at a time

- Measure your productivity 
Table 2. Awareness and expertise to improve productivity

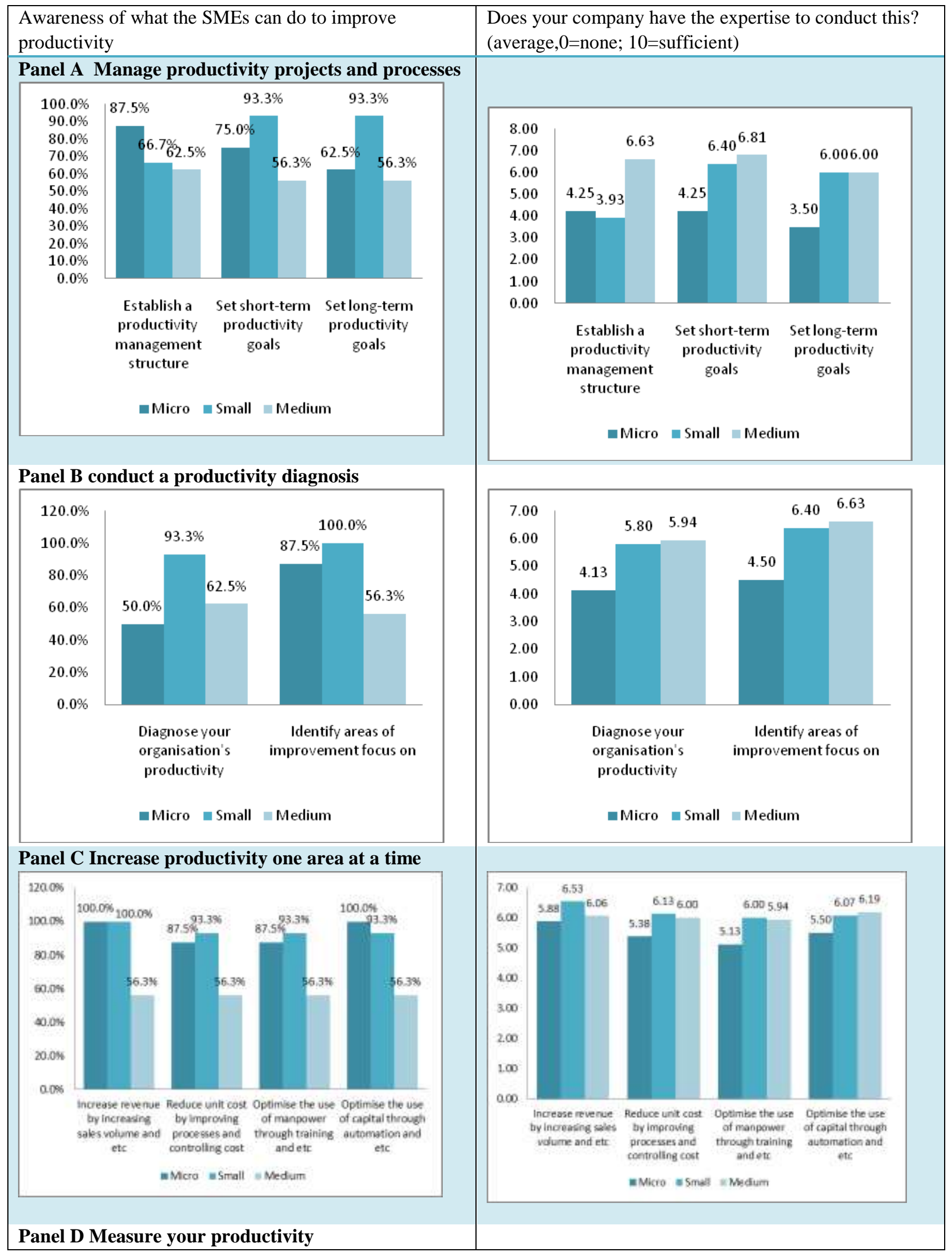




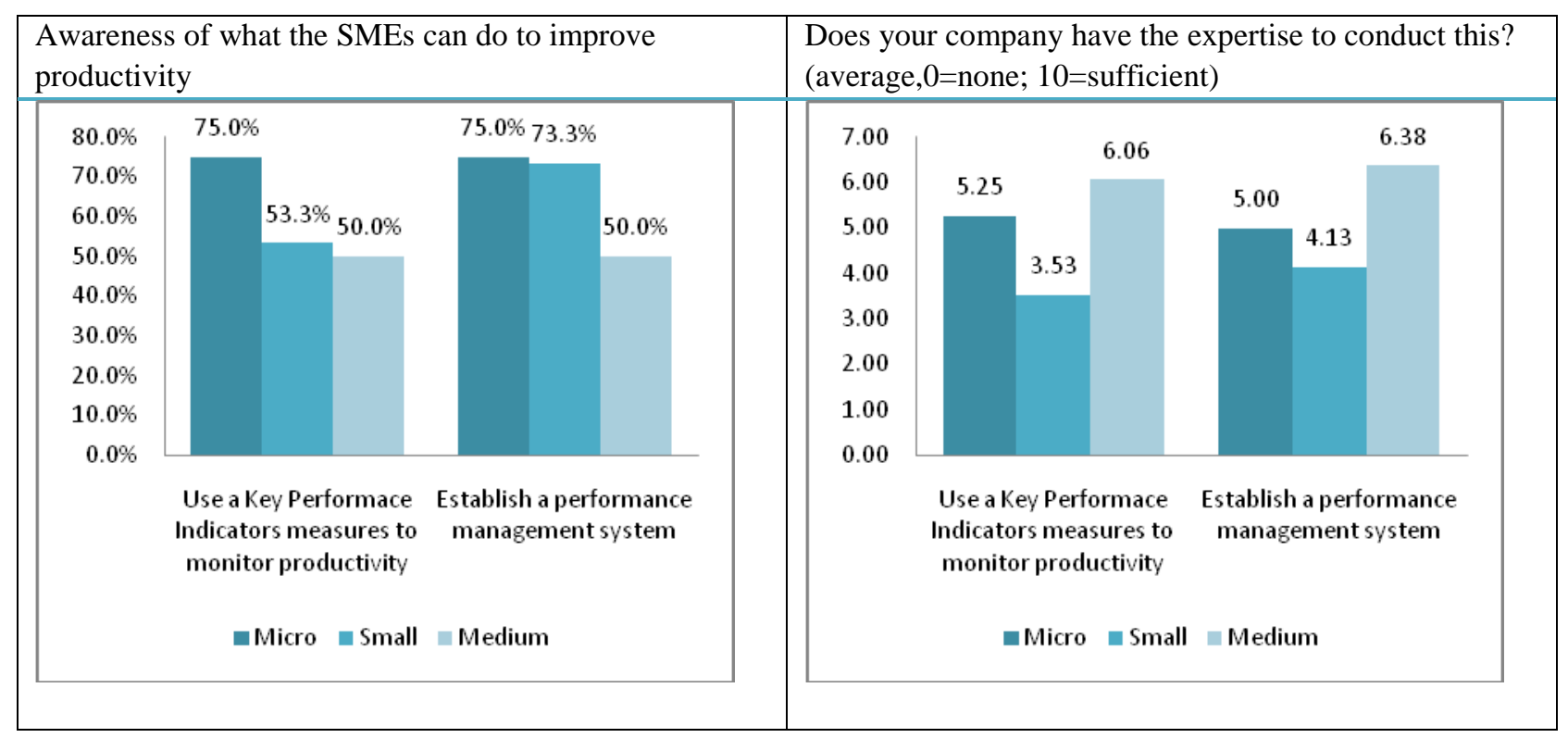

Results indicate that micro sized firms show a higher level of awareness in managing productivity projects and processes even though all the firms illustrate awareness of the practice to diagnose productivity. The level of awareness in identifying areas of improvement to focus on, is higher than the diagnostic activity. All these firms show slightly higher level of sufficiency in terms of the expertise to conduct these practices.

The micro and small sized firms reported a high level of awareness in increasing productivity in one area at a time. However, the micro sized firms lack expertise in conducting these practices. Results also show that medium sized firms are worth deliberating further because they exhibited low awareness of this practice. This could be because they have achieved an optimal level of these practices hence, were facing marginal returns for their efforts. In this regard, micro sized firms are more diligent in measuring productivity as their level of awareness in this aspect correlates with the practices in the other areas.

In looking at the four aspects noted above, it can be seen that overall, the level of awareness ranged from a satisfactory level of $50 \%$ to a very impressive level of $100 \%$. However, it appears that the SMEs in the manufacturing sector lacked the expertise to perform these practices as a means of improving productivity. This is further illustrated by all the average expertise score of below 7 .

\section{Discussion}

The measurement of productivity has most commonly involved owner-managers of small to medium- sized businesses who informally check on how efficient their staff are while on the job. In manufacturing enterprises, productivity levels were largely determined by the substitution of labour with capital, the extent to which existing capital is used efficiently, and production flows. Multi-skilling of staff through cross-training was used as a strategy by manufacturing employers to enhance productivity which is done by enabling the deployment of staff across departments. In most of these enterprises, adjustments made were the result of 'business-as-usual' practices aimed at improving efficiencies and reducing costs wherever possible, as a part of everyday management practices. Other strategies used were increasing labour productivity, lowering operational costs, changing organizational methods, enhancing training and development courses which were designed based on the four areas of practices. The overall aim is to nurture competent employees in conducting similar practices. 


\section{Conclusion}

In conclusion, it can be said that micro sized and small firms have less awareness and readiness in implementing this minimum wage policy when compared to larger firms. The findings will help employers to develop effective measures in reducing the negative impact incurred on company productivity. These measures should be further complemented by other productivity-enhancing measures such as the provision of training to up-skill workers, improvement in the quality of education, and the facilitation of investment in automation and advanced technology. With government and institutional support, as well as proper supervision and enforcement, the minimum wage policy is well-positioned to realize its goals.

\section{Acknowledgements}

We express our sincere gratitude to Associated Chinese Chambers of Commerce (ACCCIM) SERC Trust as a research grantee for this study.

\section{References}

Cairo AMC-CBE-WBG, SME Conference (2015) 14 - 15 January. Retrieved date: Oct 23, 2015 from: http://www.cbe.org.eg/NR/rdonlyres/95EA10FA-62EE-4469A40EA952FDE2B434/2737/CairoSMEConferenceJan2015Session3DatoHafsahMalaysi.pdf

Dogan, E., Wong, K.N. \& Michael, Y.M.C. (2013).Turnover, ownership and productivity in Malaysian manufacturing. Journal of the Asia Pacific Economy, 18(1), 26-50.

Frick, B., GoetzenU. \& Simmons, R.(2013). The hidden costs of high performance work practices: evidence from a large German steel company. International Labor Relation Review, 66(1), 198-224.

Fuss, C. \& Wintr, L. (2012).Rigid wages and flexible employment? Contrasting responses to firm level and sector level productivity developments. Brussels Economics Review, 55(3), 241-268.

Global Wage Report (2013). Wage and Equitable Growth. International Labour Organization, Switzerland. Available at: http://www.ilo.org/global/research/global-reports/global-wagereport/2012/WCMS_194843/lang--en/index.htm

Gomez, V.M., Fernandez, M. \& Romeu, A. (2007).The link between wages and productivity in Spain. International Review of Applied Economics, 21(2), 247-272.

Low Pay Commission Report (2011).National Minimum Wage. UK. Available at: http://www.lowpay.gov.uk/lowpay/report/pdf/Revised_Report_PDF_with_April_date.pdf

Riley, R \& Bondibene, C. (2015) Raising the standards: Minimum Wages and Firms Productivity Research Report for the National Institute of Economic and Social Research. NIESR Discussion paper No.449, May 2015.

Sin Chew Jit Poh (2013). Higher Productivity of Domestic Workers compare to Foreign Workers, 9 July. Available at http://news.sinchew.com.my/node/309392?tid=1

Shapiro, C \& Stiglitz, J. (1984).Equilibrium Unemployment as a Worker Discipline Device'. The American Economic Review, (74(3):433-444

The Edge (2012). What Malaysia's Minimum Wage Could Mean for Singapore, 12 March. Available at: http://www.theedgemalaysia.com/commentary/210246-what-malaysias-minimum-wage-could-mean-forsingapore.html

The Star (2013). Minimum Wage could 'Kill SMEs', 7 March. Available at: http://www.thestar.com.my/story.aspx?sec=b\&file=\%2F2012\%2F3\%2F7\%2Fbusiness\%2F10866794 